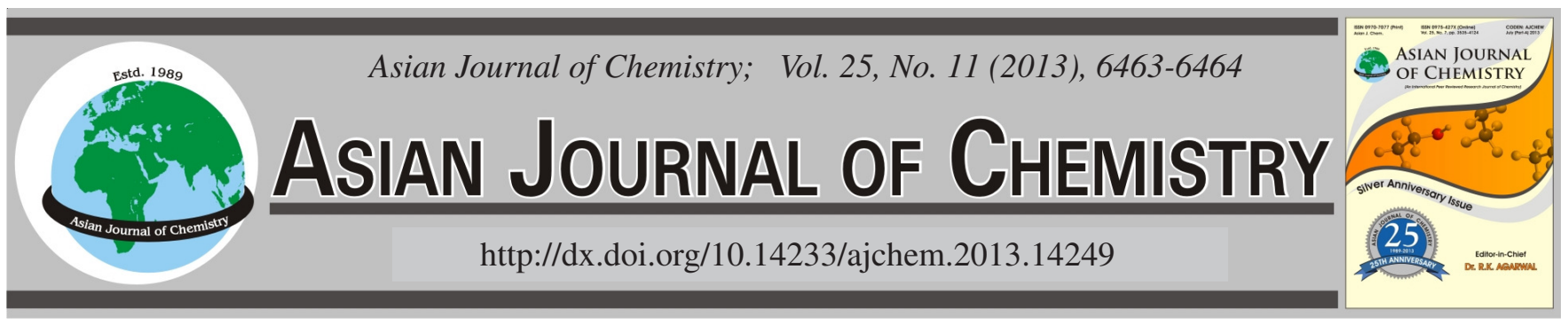

NOTE

\title{
Preparation of High Quality Ethephon Using Domestic Diester bis-(2-chloroethyl)-2-chloroethylphosphonate as Substrate
}

\author{
Wenlong Zhang and DeQun Sun*
}

Marine College, Shandong University at Weihai, Wehhua West Road No.180, Weihai 264209, P.R. China

*Corresponding author: Fax: +86 631 5688303; Tel: +86 631 5688537; E-mail: dequn.sun@ @du.edu.cn

(Received: 30 June 2012;

Accepted: 14 May 2013)

AJC-13498

\begin{abstract}
Ethephon has been widely used globally. However, few companies can manufacture high quality ethephon with content of $90 \%$ in China mainland. This work described a practical procedure, which utilizing bis-(2-chloroethyl)-2-chloroethylphosphonate $\mathbf{2}$ produced by local Chinese companies as substrate to prepare ethephon with content of over $90 \%$ and high yield.
\end{abstract}

Key Words: Ethephon, Preparation, Diester.

Ethephon 4 is a plant growth regulator and promote plant maturation. As a safe and clean product, it is worldwide used in cotton, rubber, banana, tomato, tobacco, rice and other plants. The Rhodia and The Jiangsu Electric Company Limited China are the two major producers of ethephon. The export of ethephon in China has been limited by low quality of ethephon. The content of most of the ethephon produced in China is lower than $80 \%$. In spite of some improvements on the basis of old technology made by many enterprises in the 70's, there are still some problems such as low content (60-70\%), low yield and large waste discharge ${ }^{1}$. The common synthetic route employed in preparation of ethephon is described as following (Scheme-I)

British patent ${ }^{2}$ disclosed a method which can continuously or intermittently manufacture ethephon by increasing pressure from hydrogen chloride. The united states patent ${ }^{3}$ described a process to product ethephon by adding concentrated hydrochloric acid to the reaction system and then cooling to separate phases. The united states patent ${ }^{4}$ disclosed a procedure to separate and purify the product with benzene based on previous method. All of these preparations actually share the same shortcomings, such as low content in the final products and large amount of wastes. The united states patents $^{5,6}$ reported a new strategy which used diester $\mathbf{2}$ as reaction substrate to produce high quality ethephon (content over $90 \%$ ) under high pressure of hydrogen chloride. This reaction requires high-quality substrate $\mathbf{2}$ (purity $=99 \%$ ). Since there is no substrate $\mathbf{2}$ with content or purity being reached to $99 \%$ in china mainland up to now, therefore, this process is unsuitable for China companies to produce high quality ethephon.

Few researchers in China study how to improve the content of ethephon higher than $90 \%$ via domestic technology. We reported our improved preparation by using domestic diester 2 to produce ethephon with content of over $90 \%$ in high yield and furthermore the relationship between the GC content of diester $\mathbf{2}$ and final product $\mathbf{4}$ was clarified.

Diester 2 (supplied by Shandong Dacheng pesticide company); and other commercially available materials and solvents were used without further purification. Gas chromatograph (Shimadzu): With FID detector and $2000 \mathrm{~mm} \times 3 \mathrm{~mm}$ glass or stainless steel column filled $10 \%$ SE-30/Gas chrom Q150-180 $\mu \mathrm{m}$ (80-100 mesh); NMR spectra were recorded in $\mathrm{D}_{2} \mathrm{O}$ at $400 \mathrm{MHz}$. The chemical shift values are reported on the d scale with respect to TMS $(\delta 0.00)$ as internal standards.

Typical preparation of ethephon: Diester 2 (2083 g, GC purity $87 \%, 1100 \mathrm{~mL}$ ) was added to $2 \mathrm{~L}$ high-pressure reactor (designed pressure: $2 \mathrm{Mpa}$ ). The vessel was sealed and then heated with stirring. $\mathrm{HCl}$ gas was imported when temperature was reached to $80^{\circ} \mathrm{C}$. The pressure was set to $0.5 \mathrm{Mpa}$. The reaction was heated to $150{ }^{\circ} \mathrm{C}$ with efficient stirring. The another part of diester 2 (574 g) was added after 500-600 mL of by-product 1,2-dichloroethane was distillated out. The reaction was finished until no 1,2-dichloroethane could be distillated (totally, about $1200 \mathrm{~mL}$ of 1,2-dichloroethane was collected during reaction). Then importing $\mathrm{HCl}$ gas was stopped. The reaction mixture was cooled to $120{ }^{\circ} \mathrm{C}$ and concentrated in vacuum for $1 \mathrm{~h}$. The mixture was cooled to 
<smiles>O=P(CCCl)(OCCCl)OCCCl</smiles><smiles>O=P(O)(O)CCCl</smiles>

Scheme-I: Synthetic procedure of ethephon

room temperature to give final product ethephon $\mathbf{4}$ as white solid, $1240 \mathrm{~g}$, yield $100.5 \%$. The content was $93 \%$ by GC. NMR data were in agreement with published values ${ }^{7}:{ }^{1} \mathrm{H}$ NMR $\left(\mathrm{D}_{2} \mathrm{O}\right) \delta$ ppm: $2.13\left(\mathrm{~d}, 2 \mathrm{H}, \mathrm{CH}_{2} \mathrm{P},{ }^{2} \mathrm{~J}_{\mathrm{H}-\mathrm{P}}=18.0,3.58\left(\mathrm{~m}, \mathrm{CH}_{2}\right.\right.$, $\left.\mathrm{CH}_{2} \mathrm{Cl},{ }^{2} \mathrm{~J}^{\mathrm{H}-\mathrm{P}}=14.12\right) ;{ }^{13} \mathrm{C}\left(\mathrm{D}_{2} \mathrm{O}\right) \delta \mathrm{ppm}: 30.09\left(\mathrm{~d}, 2 \mathrm{H}, \mathrm{J}_{\mathrm{P}-\mathrm{C}}\right.$ $=133.0 \mathrm{~Hz}), 37.495 \mathrm{ppm}(\mathrm{s}, 2 \mathrm{H}) .{ }^{31} \mathrm{P}\left(\mathrm{D}_{2} \mathrm{O}\right) \delta \mathrm{ppm}: 25.7$.

The conversion process of intermediate 2 into final product includings two reversible reactions (step 3 and step 4 in Scheme-I). We reasoned that the quality of final product 4 should rely upon both the quality of diester $\mathbf{2}$ and the conversion of $\mathbf{2}$ and $\mathbf{3}$. The quality of $\mathbf{4}$ should be improved if both of intermediate $\mathbf{2}$ and $\mathbf{3}$ can be converted completely into next product respectively. One important strategy to fulfill this aim is to remove by-product (1,2-dichloroethane) from reaction both in step 3 and step 4 continuously. Another way is to use good quality diester $\mathbf{2}$. In our preparation, domestic diester $\mathbf{2}$ was used as starting reactant, however, the procedure reported in literatures was improved, especially by removing 1,2dichloroethane from reaction during the process, so that both diester $\mathbf{2}$ and intermediate $\mathbf{3}$ could have excellent conversion. Finally, the content and yield of ethephon were achieved over $90 \%$ and nearly quantitative respectively. Furthermore, the relationship between the GC content of diester $\mathbf{2}$ and final product $\mathbf{4}$ showed that quality of ethephon would rise with increasing of the GC content of diester $\mathbf{2}$. The content of $\mathbf{4}$ was about $84.0 \%$ to $89.2 \%$ when the GC content of $\mathbf{2}$ was 78 to $83 \%$ (Table-1, entry 1-4) and it could reach over $90 \%$ while the GC content of diester 2 was $87 \%$ (Table-1, entry 5 and 6).

\begin{tabular}{ccc}
\multicolumn{3}{c}{ TABLE-1 } \\
\multicolumn{3}{c}{$\begin{array}{c}\text { INFLUENCE OF GC CONTENT OF DIESTER 2 } \\
\text { ON ETHEPHON QUALITY }\end{array}$} \\
\hline Entry & GC content (\%) of diester 2 & Content of ethephon (\%) \\
& {$[$ Ref. 8] } & [Ref. 9] \\
\hline 1 & 78 & 84.0 \\
2 & 83 & 89.2 \\
3 & 82 & 87.7 \\
4 & 78 & 85.2 \\
5 & 87 & 93.1 \\
6 & 87 & 92.9 \\
\hline
\end{tabular}

\section{Conclusion}

Through the improved process, the good quality ethephon with content of over $90 \%$ were obtained by using domestic diester. The research work showed a clear relationship between GC content of diester and quality of ethephon and this indication could be valuable for production of high quality ethephon.

\section{REFERENCES}

1. H.M. Zhang, Shanxi Sci. Technol., 6, 53 (2001).

2. S. Gerhard, R. Karl and S. Otto, Process for the Manufacture of 2-Chloroethane-Phosphonic acid: GB patent, 1373513 (1974).

3. D.I. Randall and C. Vogel, Preparation of 2-Haloethylphosphonic Acid: US Patent, 3808265 (1974).

4. D.I. Randall and R.W. Wynn, Mono-2-haloethyl Esters of 2-Haloethanephosphonic Acid: US Patent, 3626037 (1971).

5. J.E. Drach and B.J. Pendell, Process for the Manufacture of Aliphatic Phosphonic Acids: US Patent, 4064163 (1977).

6. K.W. Young and J.J. Zullo, Process for the Production of Aliphatic Phosphonic Acid: US Patent, 4728466 (1988).

7. L. Cauret, J.C. Brosse, D. Derouet and H. De Livonnière, Synth. Commun., 27, 647 (1997).

8. L.R. An, C.H. Wang and M.Q. Li, Jiangsu Agrochemicals, 4, 21 (1998).

9. GC internal standard method to measure content of ethephon: The ethephon was firstly converted completely into methyl ester by diazonium methane to give dimethyl 2-chloroethyl phosphonate (5), which content can be determined by GC through $10 \%$ SE-30 / Gas Chrom Q chromatography using $p$-nitrochlorobenzene as internal standard solution Through this way, the content of ethephon could be measured.

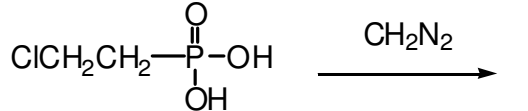

4<smiles>COP(=O)(CCCl)OC</smiles>

5 